\title{
Cystatin C and uncontrolled hypertension
}

\author{
(1) Mehmet Onur Omaygenç, ๑ Özgür Ulaş Özcan, @ Beytullah Çakal, @ Oğuz Karaca
}

Department of Cardiology, Faculty of Medicine, İstanbul Medipol University; İstanbul-Turkey

\section{ABSTRACT}

Objective: Increased serum level of cystatin C, a sensitive biomarker for renal function, seems to predict adverse cardiovascular events. We investigated the predictive value of serum cystatin $\mathrm{C}$ for controlling hypertension in an observational study.

Methods: We screened 1037 adults residing in both rural and urban communities. They were grouped based on their diagnosis and control of hypertension.

Results: Serum cystatin $C$ levels in patients with uncontrolled hypertension were higher than those in patients with controlled hypertension $(0.98 \pm 0.23 \mathrm{mg} / \mathrm{L}$ vs. $0.89 \pm 0.19 \mathrm{mg} / \mathrm{L}, \mathrm{p}=0.001)$. However, serum creatinine levels were similar between these groups $(0.72 \pm 0.20 \mathrm{mg} / \mathrm{dL}$ vs. $0.70 \pm 0.18$ $\mathrm{mg} / \mathrm{dL}, \mathrm{p}=0.89$ ). Serum cystatin C levels increased the probability of uncontrolled hypertension independent from confounding factors (odds ratio, 1.48; 95\% confidence interval, 1.09-5.64; $p=0.03$ ).

Conclusion: Subtle kidney dysfunction may be detected using serum cystatin $\mathrm{C}$ concentrations among patients with poor blood pressure control and normal serum creatinine levels. (Anatol J Cardiol 2020; 24: 309-15)

Keywords: chronic kidney disease, creatinine, cystatin C, hypertension

\section{Introduction}

Hypertension is an underdiagnosed and undertreated disease in real life (1-4). Lowering blood pressure with pharmacologic intervention has been shown to reduce cardiovascular morbidity and mortality rates (4-6). Renal control of extracellular volume plays a key role in blood pressure regulation, and chronic kidney disease (CKD) has been a well-recognized cause of uncontrolled hypertension $(7,8)$. The definition of CKD is based on the glomerular filtration rate (GFR), which has been estimated based on serum creatinine concentrations. However, the combined use of serum creatinine and cystatin $C$ levels performed better for confirmation of CKD (9). Serum cystatin $C$ is a sensitive biomarker used to measure kidney function and seems to be independent of age, sex, and muscle mass (10). Increased serum level of cystatin $C$ seems to predict adverse cardiovascular events and acts as an early marker for renal impairment (10-13). Based on these data, we hypothesized that serum cystatin C levels might predict uncontrolled hypertension in individuals with apparently normal kidney function based on serum creatinine measurements.

\section{Methods}

Patient characteristics, basic measurements, and laboratory tests

We designed an observational study to analyze serum cystatin $C$ levels to predict uncontrolled hypertension in individuals without apparent kidney failure. We screened adult patients residing in predetermined rural and urban territories. The subjects were visited at their homes and invited to participate in the survey. We assessed 1037 patients for inclusion and excluded 134 patients because of known renal disease. In the second step, 71 patients were additionally excluded due to reduced GFR, significant albuminuria ( $>30 \mathrm{mg} / 24 \mathrm{~h}$ ), and newly diagnosed hypertension. Finally, 832 patients constituted the final sample population. The patients were grouped based on their diagnosis and control of hypertension (Fig. 1). Data on social characteristics, medical history, and use of any drug were obtained using a questionnaire. Blood samples were drawn from each participant early in the morning after overnight fasting to measure the serum creatinine, glucose, and cystatin $C$ levels. The $24-h$ urine specimens were collected to measure albumin excretion rate. The measurement of serum

Address for correspondence: Dr. Mehmet Onur Omaygenç, İstanbul Medipol Üniversitesi Tıp Fakültesi, 
glucose was performed twice in individuals with glucose level of $>126 \mathrm{mg} / \mathrm{dL}$. Patients with a history of hypertension were subdivided as controlled and uncontrolled hypertension based on their blood pressure measurements (see details below). Subjects with incidental low GFR $\left(<90 \mathrm{~mL} / \mathrm{min} / 1.73 \mathrm{~m}^{2}\right)$ and newly diagnosed hypertension were also excluded for comparison by blood pressure control. The flow diagram of the participants is shown in Figure 1. All patients provided written informed consent. This study complied with the Declaration of Helsinki and was approved by the Institutional Committee on human research and registered at ClinicalTrials.gov (identifier NCT 02334033).

Blood pressure was measured from both arms by using a mercury sphygmomanometer with the participants in a sitting position after a 5-min rest. The legs of the subjects were uncrossed, and their feet were on the floor. The arms were supported at the heart level. The individuals did not have caffeine or tobacco in the 30 min before the measurement. The cuff of the sphygmomanometer was inflated rapidly to $180-200 \mathrm{~mm} \mathrm{Hg}$, then the cuff was released at a moderate rate $(3 \mathrm{~mm} / \mathrm{s})$. The first Korotkoff sound was the subject's systolic blood pressure. The point, when the sounds disappeared, was the diastolic blood pressure. Systolic and diastolic blood pressures were calculated as the mean of the two measurements from the left and right arms, which were obtained at 5-min intervals. The higher mean of the blood pressure measured from two arms was recorded for the analysis. Blood pressure was measured in the morning after

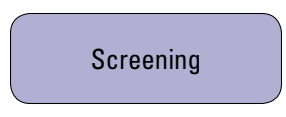

A total of 1037 individuals who gave consent for the survey were screened. Of them 134 were excluded for known chronic kidney disease. So 903 subjects were included.

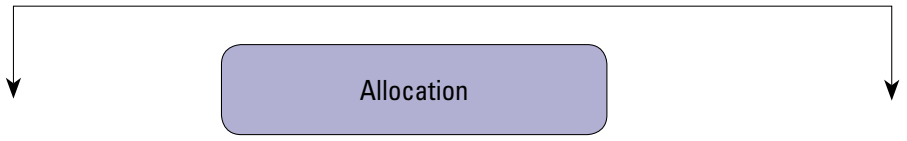

Had history of hypertension $(n=444)$
Uncontrolled hypertension $(n=254)$
Controlled hypertension $(n=190)$

Had no history of hypertension ( $\mathrm{n}=459$ ) Newly diagnosed hypertension ( $\mathrm{n}=29$ ) No diagnosis of hypertension $(n=430)$

Uncontrolled hypertension with normal creatinine levels $(n=230)$

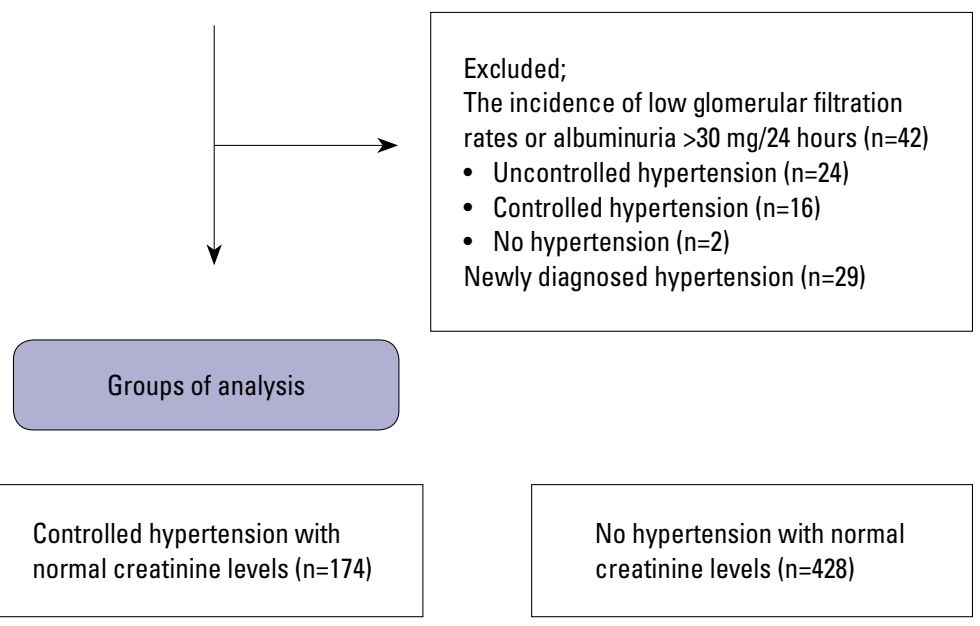

Figure 1. Flow diagram of patients. The diagram includes detailed information on the excluded patients and formation of groups 
the subjects had taken their pills. Controlled hypertension was defined as systolic blood pressure $<140 \mathrm{~mm} \mathrm{Hg}$ and diastolic blood pressure $<90 \mathrm{~mm} \mathrm{Hg}$ under antihypertensive drug treatment. Uncontrolled hypertension was defined as systolic blood pressure $\geq 140 \mathrm{~mm} \mathrm{Hg}$ or diastolic blood pressure $\geq 90 \mathrm{~mm} \mathrm{Hg}$ under antihypertensive drug treatment. We excluded 29 patients without a known history of hypertension who had high blood pressure measurements. Status of hypertension control was confirmed with ambulatory blood pressure monitoring. The cutoff values for 24-h mean recordings were identified as $140 \mathrm{~mm}$ $\mathrm{Hg}$ and $90 \mathrm{~mm} \mathrm{Hg}$ for systolic and diastolic pressure, respectively. The mean ambulatory blood pressure levels were within the defined limits in nine patients whose initial measurements were higher. Hence, they were assumed to have controlled hypertension. Based on the ambulatory recordings, the participants were divided into three groups: controlled hypertension, uncontrolled hypertension, and no hypertension.

Serum creatinine and cystatin $C$ levels were measured from venous blood samples. All analyses were performed in a central laboratory. Serum cystatin $C$ levels were measured using a particle-enhanced immunonephelometric assay (N Latex Cystatin C; Dade Behring, Deerfield, IL, USA). The inter- and intra-assay coefficients of variation were $5.1 \%$ and $4.4 \%$, respectively. Serum creatinine levels were measured using the Jaffe method (Roche Diagnostics, Indianapolis, IN, USA). GFRs were estimated using Chronic Kidney Disease Epidemiology Collaboration (CKD-EPI) equations based on serum creatinine and cystatin $C$ concentrations (14). Plasma glucose concentrations were measured using the glucose oxidase method on an auto-analyzer (Express Plus 500 Auto-analyzer CIBA-Corning, Germany).

Body mass index (BMI) was calculated as the weight in kilograms divided by the height in meters squared. Abdominal obesity was defined based on waist circumference of $>102$ and $>88$ $\mathrm{cm}$ in men and women, respectively. Waist circumference was measured using a tape measure placed around the abdomen at the upper margin of the iliac crests. The tape was positioned parallel to the floor, and the measurements were performed at the end of the expiration. Body weight, height, and waist circumference were measured by a trained surveyor while the individuals were wearing underclothes without shoes. Diabetes mellitus was diagnosed as two fasting glucose measurements $>126 \mathrm{mg} /$ $\mathrm{dL}$ or use of hypoglycemic drugs.

Sample size was calculated with assumed concentrations of serum cystatin $C$ as $0.95 \pm 0.26 \mathrm{mg} / \mathrm{L}$ and $0.89 \pm 0.23 \mathrm{mg} / \mathrm{L}$ in patients with hypertension and in the control group, respectively. The total sample size of 872 was necessary for a two-sided test with 0.95 statistical power and alpha level of 0.05 . Therefore, we screened 1037 subjects and included 903 individuals in the survey.

\section{Statistical analyses}

Data were expressed as frequencies for discrete variables and as means \pm standard deviation or median (interquartile range) for continuous variables. Shapiro-Wilk test was used to assess data distribution. Demographic continuous variables of the groups with or without controlled hypertension were compared using the Student unpaired t-test or Mann-Whitney Utest according to data distribution. The chi-squared analysis was used to assess the significance of differences between dichotomous variables. One-way analysis of variance compared the variables of the three groups when normotensive subjects were included in the analysis. Tukey test was used for post-hoc assessment of intergroup variances. Pearson test revealed correlations between blood pressure and kidney functions. In univariate logistic regression analysis, age, sex, serum cystatin $C$ and creatinine levels, presence of diabetes mellitus, and smoking status were assessed. Univariate correlates of uncontrolled hypertension with a $p<0.1$ were included in the multiple logistic regression analysis. The receiver operating characteristic (ROC) curve analyses of serum cystatin $C$ levels for the prediction of uncontrolled hypertension and determination of the cut-off point for serum cystatin $C$ levels was performed. The odds ratios of serum cystatin $C$ levels higher than the cut-off value were calculated for uncontrolled hypertension by using multiple logistic regression analysis. All tests were two-sided, and the results with $p<0.05$ were considered significant. All analyses were performed using an SPSS software package (version 20 for Windows, SPSS Inc., Chicago, IL, USA).

\section{Results}

Of 1037 individuals screened, 134 (12.9\%) patients were excluded for known CKD. Moreover, 444 (49.2\%) of the study population ( $\mathrm{n}=903$ ) had a history of hypertension compared with 459 $(50.8 \%)$ who had no history of hypertension. The rate of controlled hypertension was $42.8 \%$ (190/444). Final analyses were performed after exclusion of subjects with low GFRs or albuminuria $>30 \mathrm{mg} / 24 \mathrm{~h}(\mathrm{n}=42)$. Finally, 832 patients were included in the final sample population after excluding 29 additional subjects without a history of hypertension but with high initial blood pressure measurements. Figure 1 shows the detailed flow diagram of the subjects. Comparisons of demographic, clinical, and laboratory parameters are presented in Table 1. Subjects with hypertension were older, more likely to have abdominal obesity, and had higher $B M I$ values compared with those without hypertension. Serum cystatin C levels in patients with uncontrolled hypertension were higher those in patients with controlled hypertension $(0.98 \pm 0.23$ $\mathrm{mg} / \mathrm{L}$ vs. $0.89 \pm 0.19 \mathrm{mg} / \mathrm{L}, \mathrm{p}=0.001)$. However, serum creatinine levels were similar between these groups $(0.72 \pm 0.20 \mathrm{mg} / \mathrm{dL}$ vs. $0.70 \pm 0.18 \mathrm{mg} / \mathrm{dL}, \mathrm{p}=0.89$ ). Similarly, the mean GFR estimated by cystatin $C$ in patients with uncontrolled hypertension was lower than that in patients with controlled hypertension $(76.7 \pm 17 \mathrm{~mL} /$ $\min / 1.73 \mathrm{~m}^{2}$ vs. $\left.81.3 \pm 17.1 \mathrm{~mL} / \mathrm{min} / 1.73 \mathrm{~m}^{2}, \mathrm{p}=0.04\right)$. The mean GFRs were indifferent between the uncontrolled and controlled hypertension groups when calculated using serum creatinine levels $\left(93.8 \pm 17.2 \mathrm{~mL} / \mathrm{min} / 1.73 \mathrm{~m}^{2}\right.$ vs. $96.8 \pm 18.8 \mathrm{~mL} / \mathrm{min} / 1.73 \mathrm{~m}^{2}$, 


\begin{tabular}{|c|c|c|c|c|c|c|c|}
\hline Characteristics & $\begin{array}{l}\text { Uncontrolled } \\
\text { hypertension } \\
(\mathrm{n}=230)\end{array}$ & $\begin{array}{c}\text { Controlled } \\
\text { hypertension } \\
(n=174)\end{array}$ & $\begin{array}{c}\text { No hypertension } \\
(\mathrm{n}=428)\end{array}$ & $P 1$ & $P 2$ & P3 & $\boldsymbol{P}$ \\
\hline Age, years & $57.3 \pm 10.6$ & $49.9 \pm 12.3$ & $41.9 \pm 11.7$ & $<0.001$ & $<0.001$ & $<0.001$ & $<0.001$ \\
\hline Male sex, $\mathrm{n}(\%)$ & $68(30)$ & $48(28)$ & $141(33)$ & 0.65 & 0.42 & 0.22 & 0.38 \\
\hline Body mass index, $\mathrm{kg} / \mathrm{m}^{2}$ & $30.9 \pm 5.9$ & $30.1 \pm 5.4$ & $27.8 \pm 4.8$ & 0.19 & $<0.001$ & $<0.001$ & $<0.001$ \\
\hline Active smoking, $\mathrm{n}(\%)$ & $63(27)$ & $29(17)$ & $126(29)$ & 0.017 & 0.54 & $<0.001$ & 0.002 \\
\hline Diabetes mellitus, $n(\%)$ & $35(15)$ & $38(22)$ & $85(20)$ & 0.11 & 0.12 & 0.76 & 0.24 \\
\hline Abdominal obesity, $\mathrm{n}(\%)$ & $136(59)$ & 99 (57) & $133(31)$ & 0.70 & $<0.001$ & $<0.001$ & $<0.001$ \\
\hline Systolic BP, mm Hg & $164.2 \pm 20.8$ & $126.4 \pm 13.0$ & $114.6 \pm 12.6$ & $<0.001$ & $<0.001$ & $<0.001$ & $<0.001$ \\
\hline Diastolic BP, mm Hg & $98.7 \pm 11.9$ & $79.0 \pm 8.9$ & $75.2 \pm 8.0$ & $<0.001$ & $<0.001$ & $<0.001$ & $<0.001$ \\
\hline Creatinine, $\mathrm{mg} / \mathrm{dL}$ & $0.72 \pm 0.20$ & $0.70 \pm 0.18$ & $0.68 \pm 0.16$ & 0.89 & 0.15 & 0.45 & 0.14 \\
\hline Cystatin C, mg/L & $0.98 \pm 0.23$ & $0.89 \pm 0.19$ & $0.85 \pm 0.25$ & 0.001 & $<0.001$ & 0.08 & $<0.001$ \\
\hline GFR by creatinine, $\mathrm{mL} / \mathrm{min} / 1.73 \mathrm{~m}^{2}$ & $93.8 \pm 17.2$ & $96.8 \pm 18.8$ & $104.7 \pm 17.2$ & 0.36 & $<0.001$ & $<0.001$ & $<0.001$ \\
\hline GFR by cystatin $\mathrm{C}, \mathrm{mL} / \mathrm{min} / 1.73 \mathrm{~m}^{2}$ & $76.7 \pm 17$ & $81.3 \pm 17.1$ & $90.1 \pm 17.3$ & 0.04 & $<0.001$ & $<0.001$ & $<0.001$ \\
\hline GFR by creatinine and cystatin $\mathrm{C}, \mathrm{mL} / \mathrm{min} / 1.73 \mathrm{~m}^{2}$ & $84.9 \pm 17.1$ & $89.3 \pm 18.1$ & $97.6 \pm 17.7$ & 0.06 & $<0.001$ & $<0.001$ & $<0.001$ \\
\hline
\end{tabular}

Table 2. Comparison of demographic characteristics between patients with uncontrolled and controlled hypertension

\begin{tabular}{|c|c|c|c|}
\hline Characteristics & $\begin{array}{l}\text { Uncontrolled hypertension } \\
\qquad(\mathrm{n}=230)\end{array}$ & $\begin{array}{l}\text { Controlled hypertension } \\
\qquad(\mathrm{n}=174)\end{array}$ & $P$ value \\
\hline Number of antihypertensive drugs, median (IQR) ${ }^{\dagger}$ & $1(1)$ & $1(1)$ & 0.81 \\
\hline Duration of hypertension, years $\pm S D^{*}$ & $17.2 \pm 5.4$ & $12.6 \pm 4.9$ & 0.01 \\
\hline Use of ACEi/ARB, $n(\%)$ & $99(43)$ & $73(42)$ & 0.88 \\
\hline Ca channel blockers, n (\%) & $85(37)$ & $60(34.5)$ & 0.23 \\
\hline Alpha blockers, n (\%) & $15(6.5)$ & $15(8.6)$ & 0.44 \\
\hline
\end{tabular}

$\mathrm{p}=0.36)$. Comparisons of demographic characteristics regarding antihypertensive drug use between controlled and uncontrolled hypertension groups are shown in Table 2 . The duration of hypertension in patients with uncontrolled hypertension was higher than that in patients with controlled hypertension $(17.2 \pm 5.4$ years vs. $12.6 \pm 4.9, p=0.01)$. The remaining parameters were comparable between the two groups.

The correlation analyses of systolic blood pressure and kidney function parameters are shown in Table 3. The kidney function parameters based on serum cystatin $\mathrm{C}$ measurements were better correlated with systolic and diastolic blood pressure. The influence of serum cystatin $C$ levels in uncontrolled hypertension was examined by comparing the hazard ratios of various factors described previously. Univariate analysis identified age, serum cystatin $C$ levels, and active smoking as significant factors for the presence of uncontrolled hypertension. The multivariate regression model showed that age and serum cystatin $C$ levels increased the probability of uncontrolled hypertension independent from confounding factors [odds ratio (OR), 1.05; $95 \%$ confidence interval ( $\mathrm{Cl}$ ), 1.03-1.08, $\mathrm{p}<0.001$ for age; $0 \mathrm{R}, 1.48 ; 95 \%$ $\mathrm{Cl}, 1.09-5.64, \mathrm{p}=0.03$ for serum cystatin $\mathrm{C}$ levels] (Table 4). The ROC curve analysis of serum cystatin $C$ levels determined the best cut-off value for cystatin $\mathrm{C}$ as $0.98 \mathrm{mg} / \mathrm{L}$ for patients with uncontrolled hypertension, with a sensitivity of $80 \%$ and a specificity of $71 \%$ (area under the curve, $0.821 ; 95 \% \mathrm{Cl}, 0.781-0.860$, $\mathrm{p}<0.001$ ) (Fig. 2). The multiple logistic regression model showed that the $\mathrm{OR}$ of uncontrolled hypertension comparing serum cystatin C level $\geq 0.98 \mathrm{mg} / \mathrm{L}$ to $<0.98 \mathrm{mg} / \mathrm{L}$ was $3.43(95 \% \mathrm{Cl}, 2.41-4.88$, 
Table 3. Correlation analyses of systolic blood pressure and kidney function parameters

\begin{tabular}{|lcc|}
\hline Parameters & $\begin{array}{c}\text { Pearson } \\
\text { correlation } \\
\text { coefficient }\end{array}$ & P value \\
\hline SBP vs. SCre & 0.07 & 0.04 \\
SBP vs. SCys C & 0.29 & $<0.01$ \\
SBP vs. GFR estimated by SCre & -0.26 & $<0.01$ \\
SBP vs. GFR estimated by SCys C & -0.40 & $<0.01$ \\
SBP vs. GFR estimated by SCre and SCys C & -0.36 & $<0.01$ \\
DBP vs. SCre & 0.05 & 0.11 \\
DBP vs. SCys C & 0.24 & $<0.01$ \\
DBP vs. GFR estimated by SCre & -0.20 & $<0.01$ \\
DBP vs. GFR estimated by SCys C & -0.33 & $<0.01$ \\
DBP vs. GFR estimated by SCre and SCys C & -0.32 & $<0.01$ \\
\hline DBP - diastolic blood pressure; GFR - glomerular filtration rate; SBP - systolic blood \\
pressure; SCre - serum creatinine; SCys C - serum cystatin C & \\
\hline
\end{tabular}

$\mathrm{p}<0.001)$ if the reference is no hypertension, and $1.70(95 \% \mathrm{Cl}$, $1.11-2.59, p=0.001$ ) if the reference is controlled hypertension.

\section{Discussion}

We aimed to examine the predictive value of serum cystatin $C$ for uncontrolled hypertension. The prevalence of hypertension was $49.2 \%$, and the control rate of hypertension was $42.8 \%$. The present observational study showed an increased risk of uncontrolled hypertension among individuals with increased serum cystatin $\mathrm{C}$ concentrations (OR, 1.48; 95\% Cl, 1.09-5.64, $\mathrm{p}=0.03$ ).

In this study, the main distinctive features of patients with uncontrolled hypertension were increased age, active smoking, and mild renal dysfunction. Besides, patients with hypertension were more likely to be obese than those without hypertension. These findings were consistent with those of a previous large survey (15).

Inadequate salt excretion by the kidneys had been suggested to be one major contributor to hypertension, even with

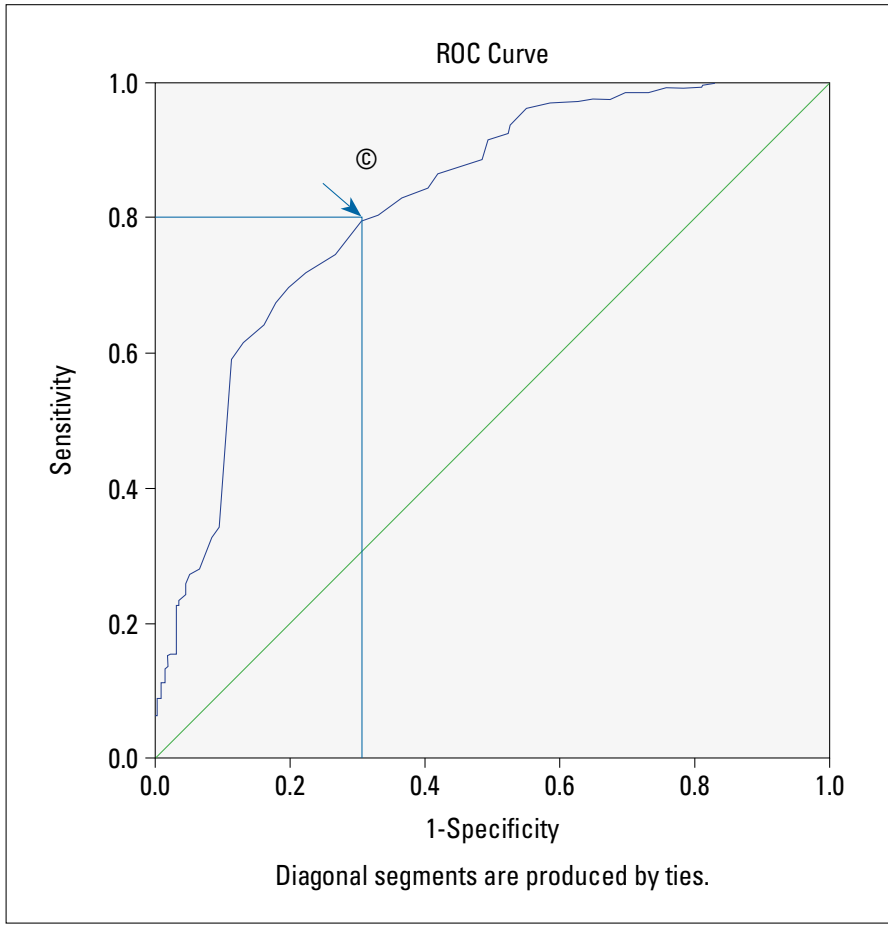

Figure 2. Receiver operating characteristic (ROC) curve analysis of serum cystatin $\mathrm{C}$ levels for the prediction of uncontrolled hypertension among patients with normal serum creatinine levels. (C)=Cut-off value for serum cystatin C: $0.98 \mathrm{mg} / \mathrm{L}$. Sensitivity, $80 \%$; specificity, $71 \%$. Area under the curve: $0.821,95 \% \mathrm{Cl}: 0.781-0.860, \mathrm{p}<0.001$

normal GFR $(7,16)$. The rate of kidney disease tends to increase over time because of longer life expectancy (17). CKD is associated with poor blood pressure control, and uncontrolled hypertension accelerates the deterioration of renal function (18-20). Therefore, blood pressure control has been established as a basic management strategy for secondary prevention of CKD (16).

Cystatin $C$ is a more sensitive biomarker than serum creatinine or estimated GFR to detect mild renal dysfunction (21). The combined use of creatinine and cystatin $C$ has been recommended to confirm the diagnosis of CKD (9). Cystatin $C$ has also added to the value of estimated GFR in determining mortality risk (22). This trial demonstrated that serum cystatin $C$ levels in patients with uncontrolled hypertension were higher than those in

Table 4. Risk predictors of uncontrolled hypertension

\begin{tabular}{|lcccccc|}
\hline Variable & $\begin{array}{c}\text { Unadjusted } \\
\text { odds ratio }\end{array}$ & $\begin{array}{c}\text { 95\% confidence } \\
\text { interval }\end{array}$ & P value & $\begin{array}{c}\text { Adjusted } \\
\text { odds ratio }\end{array}$ & $\begin{array}{c}\text { 95\% confidence } \\
\text { interval }\end{array}$ & P value \\
\hline Age & 1.06 & $(1.03-1.08)$ & $<0.001$ & 1.05 & $(1.03-1.08)$ & $<0.001$ \\
Male sex & 1.12 & $(0.72-1.76)$ & 0.61 & 1.28 & $(0.77-2.13)$ & 0.33 \\
Cystatin C & 5.90 & $(1.87-18.6)$ & 0.002 & 1.48 & $(1.09-5.64)$ & 0.03 \\
Creatinine & 1.27 & $(0.42-3.85)$ & 0.67 & & & \\
Diabetes mellitus & 1.57 & $(0.91-2.70)$ & 0.11 & & & \\
Active smoking & 1.85 & $(1.13-3.03)$ & 0.02 & 1.51 & $(0.89-2.56)$ & 0.13 \\
Duration of hypertension & 1.17 & $(0.86-1.97)$ & 0.56 & & & \\
\hline
\end{tabular}


patients with controlled and without hypertension, although all groups had normal serum creatinine concentrations. Relatively few previous studies reported an association between serum cystatin $C$ and hypertension (19, 23-25). Systolic blood pressure and pulse pressure were significantly associated with serum cystatin $\mathrm{C}$ concentrations in a previous study, even among patients with normal creatinine clearance (24). Shankar and Teppala (25) demonstrated the association of serum cystatin $C$ and hypertension among women without clinically recognized renal disease. Otsuka et al. (26) reported that elevated serum cystatin $C$ level could predict incident hypertension among non-hypertensive adults. This study demonstrated the predictive value of serum cystatin $\mathrm{C}$ for uncontrolled hypertension among patients with normal serum creatinine concentrations (26).

Decreased GFR values reflect the limited ability of the kidneys to excrete sodium, thereby increasing blood pressure. The correlation between blood pressure and GFR values showed a stronger association when the GFR was estimated by cystatin C in this trial (Table 3). We also suggested that the cut-off value for uncontrolled hypertension may be serum cystatin $C$ level $>0.98$ $\mathrm{mg} / \mathrm{L}$. The sensitivity and specificity rates of this cut-off value were high enough to be utilized in clinical practice. Hypertensive patients with serum cystatin $C$ levels $>0.98 \mathrm{mg} / \mathrm{L}$ have 1.7 -fold increased risk for uncontrolled hypertension than those with lower cystatin C levels.

The association between cystatin $C$ and uncontrolled hypertension may be suggested as a manifestation of microvascular insult of the kidneys. Such subtle end-organ damage might be undiagnosed by using serum creatinine-based measures. Our results were also consistent with a previous analysis regarding serum cystatin $C$ as a more sensitive marker than serum creatinine for mild kidney dysfunction (27).

The cost-effectiveness of screening for CKD in the general population is unknown. Screening should, therefore, focus on patients at high risk, such as those with uncontrolled hypertension. The results of this study indicate the necessity for increasing awareness of subclinical kidney dysfunction among hypertensive patients (28). Closer follow-up visits and more aggressive treatment strategy are recommended to hypertensive patients with serum cystatin C level $>0.98 \mathrm{mg} / \mathrm{L}$.

\section{Study limitations}

With regard to the sectional nature of the study, renal function was assessed with a single laboratory investigation. Following the course of renal function with cystatin $\mathrm{C}$ while monitoring the state of blood pressure control might have helped establish a more precise cause-effect relationship. Although the group of antihypertensive agents already used by the participants was specified, content of the combination treatments was not distinctively assessed with respect to their renoprotective features. Finally, the titration level of the drug(s) was not expressed as an independent variable.

\section{Conclusion}

The major novelty of this study is that subtle kidney dysfunction may be detected using serum cystatin $C$ concentrations among patients with poor blood pressure control and normal serum creatinine levels. Decreased kidney function based on serum cystatin $C$ in the presence of uncontrolled hypertension suggests a rationale for intensifying the antihypertensive regimen with agents exhibiting a preventive effect on this entity.

Conflict of interest: None declared.

Peer-review: Externally peer-reviewed.

Authorship contributions: Concept-M.0.0., Ö.U.0̈.; Design - M.0.0., Ö.U.0̈.; Supervision - 0̈.U.0̈., O.K.; Fundings - 0̈.U.0̈.; Materials - M.0.0., B.Ç., O.K.; Data collection and/or processing - M.0.0., Ö.U.0̈.; Analysis and/or interpretation - M.O.O., Ö.U.Ö., B.Ç., O.K.; Literature search - B.Ç., 0.K.; Writing - M.O.O., Ö.U.0̈.; Critical review - Ö.U.0̈.

\section{References}

1. Kearney PM, Whelton M, Reynolds K, Muntner P, Whelton PK, He J. Global burden of hypertension: analysis of worldwide data. Lancet 2005; 365: 217-23. [CrossRef]

2. Egan BM, Zhao Y, Axon RN. US trends in prevalence, awareness, treatment, and control of hypertension, 1988-2008. JAMA 2010; 303: 2043-50. [CrossRef]

3. Gu Q, Burt VL, Dillon CF, Yoon S. Trends in antihypertensive medication use and blood pressure control among United States adults with hypertension: the National Health And Nutrition Examination Survey, 2001 to 2010. Circulation 2012; 126: 2105-14. [CrossRef]

4. Onat A. Blood pressure in our community and hypertension. In: Onat A, editor. TEKHARF 2017, Leading the approach to chronic diseases in medicine. Istanbul, Logos; 2017. p.105-19.

5. Blood Pressure Lowering Treatment Trialists' Collaboration, Turnbull F, Neal B, Ninomiya T, Algert C, Arima H, et al. Effects of different regimens to lower blood pressure on major cardiovascular events in older and younger adults: meta-analysis of randomised trials. BMJ 2008; 336: 1121-3. [CrossRef]

6. Law MR, Morris JK, Wald NJ. Use of blood pressure lowering drugs in the prevention of cardiovascular disease: meta-analysis of 147 randomised trials in the context of expectations from prospective epidemiological studies. BMJ 2009; 338: b1665. [CrossRef]

7. Wadei HM, Textor SC. The role of the kidney in regulating arterial blood pressure. Nat Rev Nephrol 2012; 8: 602-9. [CrossRef]

8. Weitzman D, Chodick G, Shalev V, Grossman C, Grossman E. Prevalence and factors associated with resistant hypertension in a large health maintenance organization in Israel. Hypertension 2014; 64: 501-7. [CrossRef]

9. Inker LA, Schmid $\mathrm{CH}$, Tighiouart $\mathrm{H}$, Eckfeldt JH, Feldman $\mathrm{HI}$, Greene T, et al.; CKD-EPI Investigators. Estimating glomerular filtration rate from serum creatinine and cystatin C. N Engl J Med 2012; 367: 20-9. [CrossRef]

10. Coll E, Botey A, Alvarez L, Poch E, Quintó L, Saurina A, et al. Serum cystatin $C$ as a new marker for noninvasive estimation of glomerular filtration rate and as a marker for early renal impairment. Am J Kidney Dis 2000; 36: 29-34. [CrossRef] 
11. Keller T, Messow CM, Lubos E, Nicaud V, Wild PS, Rupprecht HJ, et al. Cystatin $C$ and cardiovascular mortality in patients with coronary artery disease and normal or mildly reduced kidney function: results from the AtheroGene study. Eur Heart J 2009; 30: 314-20.

12. Taglieri N, Fernandez-Berges DJ, Koenig W, Consuegra-Sanchez L, Fernandez JM, Robles NR, et al.; SIESTA Investigators. Plasma cystatin $C$ for prediction of 1-year cardiac events in Mediterranean patients with non-ST elevation acute coronary syndrome. Atherosclerosis 2010; 209: 300-5. [CrossRef]

13. Djousse L, Kurth T, Gaziano JM. Cystatin $C$ and risk of heart failure in the Physicians' Health Study (PHS). Am Heart J 2008; 155: 82-6.

14. Stevens PE, Levin A; Kidney Disease: Improving Global Outcomes Chronic Kidney Disease Guideline Development Work Group Members. Evaluation and management of chronic kidney disease: synopsis of the kidney disease: improving global outcomes 2012 clinical practice guideline. Ann Intern Med 2013; 158: 825-30. [CrossRef]

15. Egan BM, Zhao Y, Axon RN, Brzezinski WA, Ferdinand KC. Uncontrolled and apparent treatment resistant hypertension in the United States, 1988 to 2008. Circulation 2011; 124: 1046-58. [CrossRef]

16. Eckardt KU, Coresh J, Devuyst 0, Johnson RJ, Köttgen A, Levey AS, et al. Evolving importance of kidney disease: from subspecialty to global health burden. Lancet 2013; 382: 158-69. [CrossRef]

17. Tylicki L, Jakubowska A, Lizakowski S, Zakrzewska A, Weber E, Świetlik D, et al. Treatment of hypertension in chronic kidney disease patients under specialized care: one-center cross-sectional analyses. Blood Press 2015; 24: 79-85. [CrossRef]

18. Peralta CA, Hicks LS, Chertow GM, Ayanian JZ, Vittinghoff E, Lin F, et al. Control of hypertension in adults with chronic kidney disease in the United States. Hypertension 2005; 45: 1119-24. [CrossRef]

19. Kestenbaum B, Rudser KD, de Boer IH, Peralta CA, Fried LF, Shlipak $M G$, et al. Differences in kidney function and incident hypertension: the multi-ethnic study of atherosclerosis. Ann Intern Med 2008; 148: 501-8. [CrossRef]
20. Sarnak MJ, Greene T, Wang X, Beck G, Kusek JW, Collins AJ, et al. The effect of a lower target blood pressure on the progression of kidney disease: long-term follow-up of the modification of diet in renal disease study. Ann Intern Med 2005; 142: 342-51. [CrossRef]

21. O'Riordan SE, Webb MC, Stowe HJ, Simpson DE, Kandarpa M, Coakley AJ, et al. Cystatin C improves the detection of mild renal dysfunction in older patients. Ann Clin Biochem 2003; 40: 648-55.

22. Shlipak MG, Matsushita K, Ärnlöv J, Inker LA, Katz R, Polkinghorne $K R$, et al.; CKD Prognosis Consortium. Cystatin $C$ versus creatinine in determining risk based on kidney function. N Engl J Med 2013; 369: 932-43. [CrossRef]

23. Ozer BA, Dursun B, Baykal A, Gultekin M, Suleymanlar G. Can cystatin $C$ be a better marker for the early detection of renal damage in primary hypertensive patients? Ren Fail 2005; 27: 247-53. [CrossRef]

24. Peralta CA, Whooley MA, Ix JH, Shlipak MG. Kidney function and systolic blood pressure new insights from cystatin C: data from the Heart and Soul Study. Am J Hypertens 2006; 19: 939-46. [CrossRef]

25. Shankar A, Teppala S. Relationship between serum cystatin $C$ and hypertension among US adults without clinically recognized chronic kidney disease. J Am Soc Hypertens 2011; 5: 378-84. [CrossRef]

26. Otsuka T, Kato K, Kachi Y, Ibuki C, Seino $Y$, Kodani E, et al. Serum cystatin $\mathrm{C}$, creatinine-based estimated glomerular filtration rate, and the risk of incident hypertension in middle-aged men. Am J Hypertens 2014; 27: 596-602. [CrossRef]

27. Roos JF, Doust J, Tett SE, Kirkpatrick CM. Diagnostic accuracy of cystatin $C$ compared to serum creatinine for the estimation of renal dysfunction in adults and children--a meta-analysis. Clin Biochem 2007; 40: 383-91. [CrossRef]

28. Levey AS, Atkins R, Coresh J, Cohen EP, Collins AJ, Eckardt KU, et al. Chronic kidney disease as a global public health problem: approaches and initiatives - a position statement from Kidney Disease Improving Global Outcomes. Kidney Int 2007; 72: 247-59. [CrossRef] 